\title{
Bird rookeries have different effects on different feeding guilds of herbivores and alter the feeding behavior of a common caterpillar
}

\author{
Ian S. Pearse
}

Received: 29 October 2009/Accepted: 29 July 2010/Published online: 12 August 2010

(C) The Author(s) 2010. This article is published with open access at Springerlink.com

\begin{abstract}
Aggregations of nesting birds are common in many landscapes and have a broad impact on their surrounding habitat through the nutrient input and disturbance of their guano depositions. Ecological theory makes specific predictions about how disturbances or nutrient pulses will affect the interactions between different trophic levels of organisms. This study dissects the effects of a multispecies bird rookery on plant-herbivore interactions on coast live oak trees (Quercus agrifolia). I found that different feeding guilds of herbivores were affected in opposing directions by the rookery. I observed less chewing damage within the rookery than outside, but more damage from piercing/sucking and galling herbivores within the rookery than outside. To understand why chewing guild herbivores are negatively affected by the environmental impacts of the rookery, I explored the behavioral response of a specialist caterpillar (Phryganidia californica) to various rookery conditions. Bird guano had a direct negative impact on $P$. californica foraging. $P$. californica movement was impaired by guano addition to twigs, and caterpillars preferred to eat leaves without guano on them. The rookery also had an indirect negative effect on $P$. californica foraging, as $P$. californica preferred clean leaves from forest areas outside of the rookery over clean leaves from within the rookery. This study suggests that while it may be possible to make accurate predictions about the effect of large events (such as rookery formation) on different trophic levels, understanding the response of
\end{abstract}

Handling Editor: Gimme Walter.

I. S. Pearse $(\bowtie)$

Department of Entomology, UC Davis, One Shields Ave,

Davis, CA 95616, USA

e-mail: ispearse@ucdavis.edu individual species within that trophic level requires an understanding of aspects of their natural history—such as feeding mode and behavior.

Keywords Nutrient pulse - Disturbance - Guano · Rookery $\cdot$ Herbivory

\section{Introduction}

The effect of large scale disturbances or resource additions on the interactions between organisms has been addressed by ecological theory, and specific predictions can be made about the effects of perturbations on different trophic levels of organisms (Bender et al. 1984). In the case of a resource addition, a bottom-up flow of resources (starting at the directly subsidized level) may increase the abundance or biomass of organisms at multiple trophic levels and lead to novel outcomes of trophic interactions (Polis et al. 1997). The loss of trophic levels of organisms via disturbance may have a negative effect on organisms that feed on them or act as a release to organisms that are preyed upon by them or compete with them (Menge and Sutherland 1987). While models predict that changes in the dynamics of organisms within a trophic level will occur after disturbance-such as different outcomes of competition or differential ability to utilize novel resources (Hastings 1980; Nee and May 1992) - it is difficult to predict the specific effects of a disturbance on different members of a trophic level without knowledge of their life history traits. Here, I explore the effect of an aggregation of nesting aquatic birds on different feeding guilds of herbivorous insects and explore the mechanism of inhibition of one of these guilds.

Bird rookeries are dramatic and relatively common features of riparian and coastal habitats. Aggregations of 
birds often roost in the same area for multiple years forming persistent patches (Beletsky 2006). Birds alter their roosting habitat by depositing guano or other detritus, foraging, building nests, attracting predators and parasites, and dispersing plant seeds (Ellis 2005). Each of these alterations likely has a systematic effect on the ecological interactions between organisms that otherwise use that habitat—such as plants and their herbivores.

Guano deposition is likely one of the largest and most universal effects that bird rookeries have on their environment. Large rookeries may cover trees, ground, or other substrate with centimeters of guano. This guano may directly alter the ability of plants to photosynthesize or herbivores to access plant material and move throughout their habitat (Weseloh and Brown 1971). It may have a fertilization effect to plants, thus acting as a resource pulse, which could have effects throughout the food web or act as a food source to microbial or animal communities (Hobara et al. 2005). It could also have a toxic effect on plants in high concentrations or be repulsive to herbivores (Mulder and Keall 2001). Because of the extent of habitat alteration that bird rookeries bring to their environment, it may be difficult to make predictions about how the rookery will affect different organisms. Categorization of the community of organisms affected by the rookery into trophic levels or guilds may help to predict the fate of those community members in a rookery.

This study attempts to define the effect of a bird rookery on herbivory rates by insects in different feeding guilds. Because of their different feeding mechanisms and life history strategies, various aspects of rookery formation may affect the abundance of such insects differentially. The leaf damage caused by different herbivore feeding guilds to 57 oak species was best predicted by different leaf traits, such as tannin content for chewing insects and leaf phenology for miners (Pearse and Hipp 2009). Likewise, guano may limit the movement of flightless stages of insects (such as caterpillars) but not flying insects. I observed different herbivory types ("chewing", caused mostly by caterpillars; "necrosis", caused by piercing/sucking herbivores and "galling", caused by cynipid wasp larvae) on coast live oak trees (Q. agrifolia) within or outside of a bird rookery to determine the general effect of the rookery on different guilds of herbivorous insects. While such a case study cannot generalize across all guilds or disturbances, such studies form the foundation of broader comparisons, which can draw such generalities (Yang et al. 2008).

I also isolate some of the mechanisms by which rookeries alter plant-herbivore interactions. Specifically, I test whether guano deposition affects the foraging behavior or feeding preference of Phryganidia californica Packard [Notodontidae] caterpillars (a leaf chewing herbivore). I also test whether clean leaves that have been exposed to a bird rookery are as preferable to $P$. califonica as leaves from outside of the rookery to assess whether any systemic effect of the rookery on leaf quality can be discerned.

\section{Methods}

Description of system \& oak moth colony

Since 2001, several species of wetlands birds (blackcrowned night heron, snowy egret, cattle egret, and great egret) have roosted in part of the oaks collection of the University of California-Davis arboretum. Birds arrive in early summer and maintain high nesting populations until fall. In 2005, ca. 631 nests were counted (UC Davis Arboretum 2009). Based on the presence of crustacean carapaces and claws in the fecal matter, the birds presumably feed along the floodplains of the nearby Sacramento River and Putah Creek (personal observation). A stand of ca. 50-year-old coast live oaks (Quercus agrifolia) lies within the rookery. Each year since 2003, entire branches (including twigs, leaves, etc.) of these trees have been covered in bird guano from the nesting herons. Q. agrifolia trees of a similar age to those in the arboretum (rookery) stand in neighboring UC Davis properties and have not been inhabited by the herons.

Q. agrifolia is the primary host of the California oak moth, Phryganidia californica Packard (Lepidoptera: Notodontidae), which completes all life stages on that tree (Harville 1955). A colony of $P$. californica was started from eggs and adults collected from $Q$. agrifolia trees near Santa Cruz (36.9902 N, 122.0367 W) on June 20, 2007. The colony was maintained on cuttings of $Q$. agrifolia throughout the study. First generation 4-5th instar caterpillars from this colony were used to assay the quality of $Q$. agrifolia foliage with and without guano and other effects associated with the rookery as described below.

Field damage estimates and native herbivory communities

While $Q$. agrifolia is native to the coast and not to the Central Valley of California, where this study was conducted, many species of herbivorous insects feed on urban or naturalized stands of Q. agrifolia in the Central Valley region. The primary insect damage observed on these trees could be recognized as chewing, necrotic (caused by piercing/sucking insects), or galling. In August 2008, 20 leaves on each of 12 trees were arbitrarily chosen from the canopy between 7 and 20 feet above the ground, and scored visually for percent damage (area damaged or removed/total leaf area) by each feeding type using a clear grid. Trees were assigned to the "rookery" if they had 
multiple individual herons or egrets nesting in them and clear presence of guano on at least part of the tree. Contemporaneous insect collections from varous local stands of $Q$. agrifolia indicated that several chewing lepidopteran species were abundant: Bucculatrix sp. (Bucculatricidae) and Archips argyrospila (Tortricidae); piercing-sucking or cell-feeding arthropod herbivores (which induce necrotic spotting) including aphids, whiteflies, thrips, various cicadellid hoppers, and erineum mites; and hymenopteran gallers, Dryocosmus dubiosus and Callirhytis quercuspomiformis (Cynipidae).

Guano collection

Leaves, twigs, and litter covered in bird guano were collected from the rookery. The guano was washed from the plant material with water, and the guano-suspension was dried to a paste.

"Y" twig choice tests

In July 2007, twigs (ca. $15 \mathrm{~cm}$ long) from non-rookery Q. agrifolia trees were gathered and cut into a "Y" shape such that the main stem led to two equal branches. One branch was arbitrarily assigned a treatment, while nothing was applied to the other branch. Each Y-twig was randomly assigned to either a water $(n=25)$ or guano $(n=50)$ choice test. In the water choice test, one fork of the twig was dipped in water and then dried, while the other fork was not dipped in water. In the guano choice assay, one fork of the twig was chosen arbitrarily, dipped in guano suspension, and dried, while the other fork was not dipped in guano suspension. A 4 or 5 th instar $P$. californica individual was placed at the base of the twig, which was stuck in sand such that the caterpillar, in walking up the twig, would encounter the "Y". In all choice tests, the caterpillar chose one fork of the "Y" within $10 \mathrm{~min}$.

Leaf choice tests

In July 2007, 3 choice tests were conducted to test the feeding preference of $P$. californica caterpillars between different treatments of $Q$. agrifolia leaves. In all tests, two leaves of each treatment were placed in a large Petri dish such that leaves of treatment A would be at $0^{\circ}$ and $180^{\circ}$, and leaves of treatment B at $90^{\circ}$ and $270^{\circ}$. A 4 th or 5 th instar $P$. californica individual was placed in the center of the dish at a random orientation. The experiment was terminated after 2-3 days at which point the leaves were scanned and scored for percent damage.

Leaves were arbitrarily collected for choice tests that compared (1) leaves from the rookery that had guano on them $(>25 \%$ leaf area covered) versus leaves from the same trees that had no guano, (2) clean leaves from the trees outside of the rookery to which guano-suspension had been applied versus clean leaves from the same trees to which no guano had been applied, and (3) leaves from the rookery that had no guano on them versus leaves from forest outside of the rookery (which also had no guano). Only fully-expanded first-year leaves were used for feeding assays.

\section{Statistics}

The twig choice tests were analyzed using Pearson's $\chi^{2}$ tests. Feeding choice tests and degrees of herbivory within or outside of the rookery were compared using t-tests. When data did not conform to the normality assumption of ANOVA, and normality could not be restored using transformations, a Kruskal-Wallis test was performed. Power analyses of preliminary choice assays informed the sample size of subsequent choice assays. JMP (SAS Institute, Cary, North Carolina) was used for all statistical analyses.

\section{Results}

The effect of a bird rookery on different types of herbivory

Chewing damage on Q. agrifolia leaves was less on trees inside the rookery than on trees outside of the rookery (Fig. 1a, Kruskal-Wallis test, $n=6, \quad P=0.0057$ ). Necrotic damage (black or brown spots on the leaves) caused by piercing/sucking insects was greater on trees within the rookery than on trees outside of the rookery (Fig. 1b, $t$-test, $n=6, P=0.0354$ ). Galling rates differed marginally between trees within or outside of the rookery, and tended to be higher on trees within the rookery (Fig. 1c, $t$-test, $n=6, P=0.059$ ).

\section{The effect of guano on herbivore movement}

When placed on a "Y-twig" on which one branch was a clean control and the other branch had guano added along its entire length, $P$. californica caterpillars chose the clean fork significantly more often than the fork with added guano (Fig. 2; Pearson's $\chi^{2}$ test $-P=0.007, n=50$ ). When given the choice between twig forks with or without the addition of water, there was no preference (Fig. 2; Pearson's $\chi^{2}$ test $-P=0.549, n=25$ ).

The effect of guano or rookery presence on herbivore feeding preference

When given a choice to feed on $Q$. agrifolia leaves that were clean or had naturally occurring guano, $P$. californica 
Chewing Damage
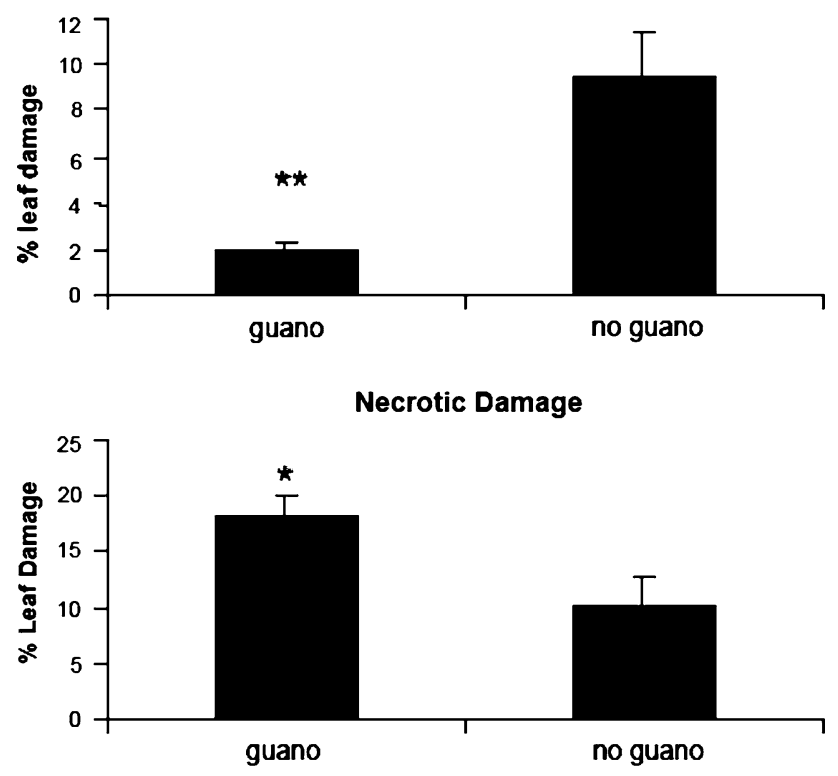

Galling Damage

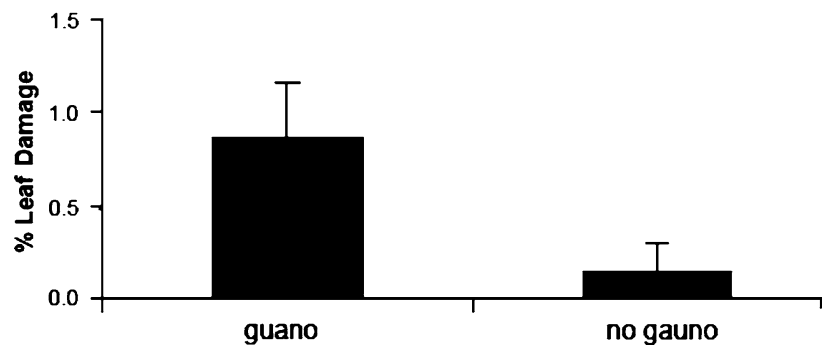

Fig. 1 The percent a chewing, b necrotic, or $\mathbf{c}$ galling leaf damage on $Q$. agrifolia trees $(n \sim 6)$ with or without guano (i.e. inside or outside of a natural bird rookery). * Significant difference at $P<0.05$; ** significant difference at $P<0.005$ using a $t$-test where homogeneity of variance (HOV) could be upheld $(\mathbf{b}, \mathbf{c})$ and a Wilcoxon test where the data deviated from HOV (a). Error bars represent standard error

caterpillars fed more often on clean leaves (Fig. 3a, paired $t$-test, $n=20, P=0.013)$. When the guano was applied experimentally to leaves, the caterpillars responded similarly, feeding more often on clean leaves (Fig. 3b, paired $t$ test, $n=14, P=0.0005)$. Naturally guano-covered leaves were marginally smaller than clean leaves from within the rookery ( $t$-test, $n=40, P=0.06$ ).

$P$. californica caterpillars also preferred clean leaves that were from forest areas away from the bird rookery more than clean leaves from within the rookery (Fig. 3c, paired $t$-test, $n=32, P=0.012$ ). Due to the bulk sampling design, the implications of this test (Fig. 3c) could be confounded by differences in caterpillar preference between individual trees (i.e. I assumed a homogeneous preference for different trees within or outside of the rookery). There was no significant difference in total leaf size between clean leaves from within the rookery and

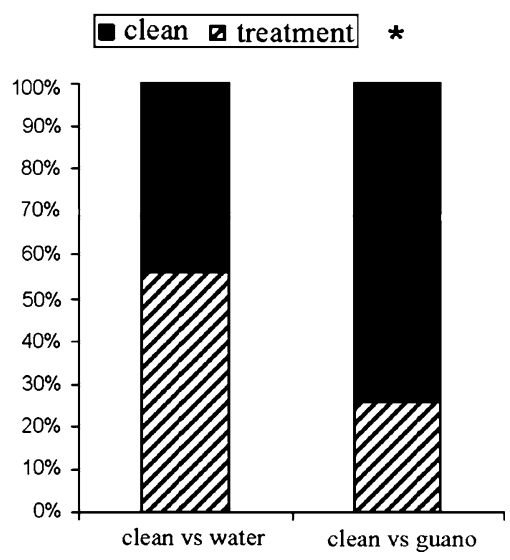

Fig. 2 "Y-twig" choice assays of Phryganidia caterpillars. Caterpillars were placed at the bottom of a Y-branching $Q$. agrifolia twig. One arm of the twig was randomly assigned a treatment of either water $(n=25)$ or guano solution $(n=50)$. The water or guano was allowed to dry and the other arm was left clean. The first branch that the caterpillar explored was recorded. Asterisk indicates a significant difference $(P<0.05)$ in caterpillar preference between treated or untreated branches using Pearson's $\chi^{2}$ test

clean leaves from outside of the rookery ( $t$-test, $n=64$, $P=0.25)$.

\section{Discussion}

Bird rookeries can have many incidental effects on the diverse organisms within their environment. This study suggests that bird rookeries have radically different effects on different feeding guilds of insects-even though each of these insects is at the same trophic level and feeds predominantly on the same host plant species (Q. agrifolia). Trees within a bird rookery suffered less chewing damage than did neighboring trees, whereas levels of necrotic damage (caused largely by piercing-sucking insects) and galling damage were both higher on trees within the rookery than on trees in surrounding areas (Fig. 1).

Why do some types of herbivores seem to benefit from the presence of nesting birds while others are negatively affected? It is unlikely that the presence of the birds directly caused the difference in herbivore guilds, as the birds tend to forage away from their nesting site. The stress imparted by guano deposition may alter leaf quality (Schmidt et al. 2004), affect plant biomass (Sanchez-Pinero and Polis 2000), or modulate the plant's response to herbivory of different types. Many piercing-sucking insects tend to perform better on stressed or senescent leaf tissue (White 1984, but see Huberty and Denno 2004), whereas chewing damage tends to accumulate more often on unstressed, young leaf tissue in oak trees (Feeny 1970), although Onuf et al. (1977) observed a greater abundance of 5 lepidopteran herbivores on a mangrove island with a 

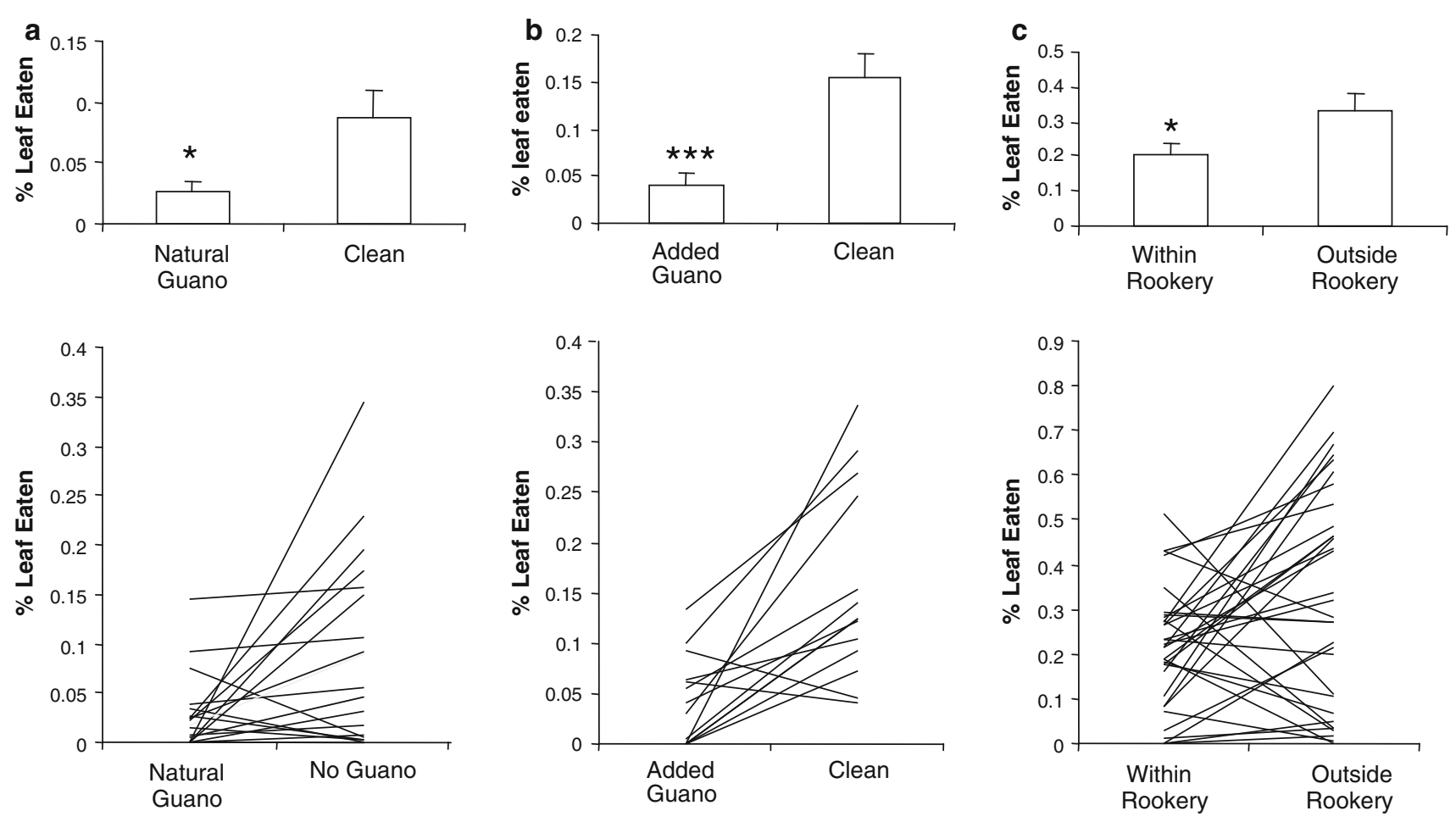

Fig. 3 Feeding choice assays of Phryganidia caterpillars on $Q$. agrifolia leaves a that were collected with or without naturally occurring guano $(n=20)$ b that were collected clean but with or without added guano $(n=14)$, and $\mathbf{c}$ that were clean but from forest areas within or outside of the bird rookery $(n=32)$. Caterpillars were placed in a feeding arena with 2 leaves of each treatment for 3 days.
At the end of this time, leaves were scanned and scored for percent damage. Differences between treatments were tested using a paired $T$ test or Kruskal-Wallis test (where HOV could not be upheld). Error bars represent standard error; each line in the bottom panel represents an individual choice test. $*$ Significant at $P<0.05$; *** significant at $P<0.0005$ pelican and egret rookery than on an island without a rookery. Fertilization effects by the guano may positively affect phloem-feeding insects, which are thought to be more nitrogen-limited than chewing herbivores (White 1984). Feller and Chamberlain (2007) similarly found differences in the effect of fertilization on herbivores with different feeding types and varying degrees of categorized "top-down limitation". Alternatively, incidental differences in the life history of insects in different feeding guilds may affect how each is able to access resources in the rookery. That is, most chewing insects in this system are immature lepidopterans, which do not fly while they are still feeding, whereas most piercing-sucking insects are hemimetabolous and feed during their often-winged adulthood. Thus, guano may be more of an impediment to non-mobile herbivores such as caterpillars. Additionally, guano can dramatically alter the atmospheric $\mathrm{pH}$ (Schmidt et al. 2010), which may have a greater effect on caterpillars than on hemimetabolous insects. Another possibility could be that bird nesting behavior directly affects lepidopteran herbivores. The birds are likely to disturb and shake branches, and this may act as a non-consumptive predator effect (sensu Sih et al. 1985) to inhibit oviposition by adult moths or reduce larval foraging. Ultimately, the net effect of a rookery on the composition of herbivore communities will be a factor not only of the effect of birds as a potential predator, but also of the nutrient enrichment to the plants, acute toxicity of guano components to the plants, the direct effects of inorganic compounds on the insects, and changes to habitat structure by the nesting birds.

This study showed that guano from bird rookeries affects the behavior of a chewing guild herbivore, Phyganidia californica, in several ways. Caterpillars avoided moving over twigs with guano (Fig. 2), suggesting that guano deposition in a bird rookery may inhibit the movement of caterpillars between food sources. P. californica caterpillars also preferred to eat clean leaves from the rookery over leaves that had guano on them (Fig. 3a). Moreover, experimentally adding guano to leaves had a qualitatively similar effect (Fig. 3b), suggesting that guano has a negative effect on caterpillar feeding. Additionally, $P$. californica caterpillars preferred clean leaves from outside of the rookery as opposed to clean leaves from within (Fig. 3c), suggesting that systematic stress to plants or induction of defenses by plants within the rookery negatively affects caterpillar feeding. In each of these tests there was a high variation in the preference 
of caterpillars suggesting that the feeding of some individuals may be more inhibited than others by the presence of guano.

Mechanistically, it is likely that guano impacts chewing herbivores both directly and via the plant's response to the guano. Guano dramatically alters soil and atmospheric ammonium content (Schmidt et al. 2004; Schmidt et al. 2010). An acute level of ammonium is directly toxic to aquatic invertebrates (Xiang et al. 2010) and has been shown to activate an oxidative response in plants (Nimptsch and Pflugmacher 2007), a pathway that is often implicated in plant defense against herbivores. Moths are typically more motile than caterpillars, so the abundance of lepidopteran herbivores on a given tree is likely driven by the oviposition behavior of the adult moth. This suggests that adult moths may avoid placing their offspring on guano-covered trees, which inhibit larval feeding behavior.

There is a great deal of interest in understanding the ecological consequences of large disturbance events such as hurricanes, floods, or fires (Hunter and Forkner 1999; Spiller and Agrawal 2003; Vervuren et al. 2003; Whalen 1995) and large resource additions such as oak masting, seaweed deposition, and periodic insect emergences (Polis and Hurd 1996; Schmidt and Ostfeld 2008; Yang 2004; Yang et al. 2008). The predictability of a resource pulse or disturbance (i.e. whether it is periodic, sustained, or ephemeral) along with aspects of the system that it interrupts (i.e. the productivity or resilience of the ecosystem) have both been documented as important predictors of the magnitude of the effect of a resource pulse on organisms within the system (Yang et al. 2008). In this case, rookery formation is somewhat predictable and periodic (birds have nested beginning in early summer and ending in fall for nearly a decade). Many generalities can be drawn about the effect of large events on different trophic levels within a community (Hastings 1980; Polis et al. 1997), however, this study shows that insects, even at the same trophic level, and which all feed on the same plant species, display different responses to the large disturbance/resource pulse of rookery formation. This study also suggests that differences in life history traits and feeding preferences between guilds helps to explain why some herbivores benefit from rookery formation, while others are negatively impacted.

Acknowledgments I would like to thank Jill Baty and Michael Valainis for help in the field. This manuscript was substantially improved after edits by Rick Karban and Louie Yang and two anonymous reviewers. The UC Davis Arboretum provided logistical support for this study.

Open Access This article is distributed under the terms of the Creative Commons Attribution Noncommercial License which permits any noncommercial use, distribution, and reproduction in any medium, provided the original author(s) and source are credited.

\section{References}

Beletsky L (2006) Birds of the world. John Hopkins University Press, Baltimore

Bender EA, Case TJ, Gilpin ME (1984) Perturbation experiments in community ecology - theory and practice. Ecology 65:1-13

Ellis JC (2005) Marine birds on land: a review of plant biomass, species richness, and community composition in seabird colonies. Plant Ecol 181:227-241

Feeny P (1970) Seasonal changes in oak leaf tannins and nutrients as a cause of spring feeding by winter moth caterpillars. Ecology $51: 565$

Feller IC, Chamberlain A (2007) Herbivore responses to nutrient enrichment and landscape heterogeneity in a mangrove ecosystem. Oecologia 153:607-616

Harville JP (1955) Ecology and population dynamics of the California oak moth Phryganidia californica Packard (Lepidoptera: Dioptidae). Microentomology 20:83-166

Hastings A (1980) Disturbance, coexistence, history, and competition for space. Theor Popul Biol 18:363-373

Hobara S, Koba K, Osono T, Tokuchi N, Ishida A, Kameda K (2005) Nitrogen and phosphorus enrichment and balance in forests colonized by cormorants: implications of the influence of soil adsorption. Plant Soil 268:89-101

Huberty AF, Denno RF (2004) Plant water stress and its consequences for herbivorous insects: a new synthesis. Ecology 85:1383-1398

Hunter MD, Forkner RE (1999) Hurricane damage influences foliar polyphenolics and subsequent herbivory on surviving trees. Ecology 80:2676-2682

Management Plan Declaration (2009) UC Davis Heronry management plan. In: UC Davis Arboretum, vol 2009, Davis. http:// arboretum.ucdavis.edu/documents/FAQonheronry1_16_09.pdf

Menge BA, Sutherland JP (1987) Community regulation—variation in disturbance, competition, and predation in relation to environmental-stress and recruitment. Am Nat 130:730-757

Mulder CPH, Keall SN (2001) Burrowing seabirds and reptiles: impacts on seeds, seedlings and soils in an island forest in New Zealand. Oecologia 127:350-360

Nee S, May RM (1992) Dynamics of metapopulations-habitat destruction and competitive coexistence. J Anim Ecol 61:37-40

Nimptsch J, Pflugmacher S (2007) Ammonia triggers the promotion of oxidative stress in the aquatic macrophyte Myriophyllum mattogrossense. Chemosphere 66:708-714

Onuf CP, Teal JM, Valiela I (1977) Interactions of nutrients, plantgrowth and herbivory in a mangrove ecosystem. Ecology 58: $514-526$

Pearse IS, Hipp AL (2009) Phylogenetic and trait similarity to a native species predict herbivory on non-native oaks. Proc Natl Acad Sci USA 106:18097-18102

Polis GA, Hurd SD (1996) Linking marine and terrestrial food webs: allochthonous input from the ocean supports high secondary productivity on small islands and coastal land communities. Am Nat 147:396-423

Polis GA, Anderson WB, Holt RD (1997) Toward an integration of landscape and food web ecology: the dynamics of spatially subsidized food webs. Annu Rev Ecol Syst 28:289-316

Sanchez-Pinero F, Polis GA (2000) Bottom-up dynamics of allochthonous input: direct and indirect effects of seabirds on islands. Ecology 81:3117-3132

Schmidt KA, Ostfeld RS (2008) Numerical and behavioral effects within a pulse-driven system: consequences for shared prey. Ecology 89:635-646

Schmidt S, Dennison WC, Moss GJ, Stewart GR (2004) Nitrogen ecophysiology of Heron Island, a subtropical coral cay of the Great Barrier Reef, Australia. Funct Plant Biol 31:517-528 
Schmidt S et al (2010) Atmospheric concentrations of ammonia and nitrogen dioxide at a tropical corla cay with high seabird density. J Environ Monitor 12:460-465

Sih A, Crowley P, Mcpeek M, Petranka J, Strohmeier K (1985) Predation, competition, and prey communities - a review of field experiments. Annu Rev Ecol Syst 16:269-311

Spiller DA, Agrawal AA (2003) Intense disturbance enhances plant susceptibility to herbivory: natural and experimental evidence. Ecology 84:890-897

Vervuren PJA, Blom CWPM, de Kroon H (2003) Extreme flooding events on the Rhine and the survival and distribution of riparian plant species. J Ecol 91:135-146

Weseloh DV, Brown RT (1971) Distribution of plants within a heron rookery. Am Midl Nat 86:57-64
Whalen RJ (1995) The ecology of fire. Cambridge University Press, Cambridge

White TCR (1984) The abundance of invertebrate herbivores in relation to the availability of nitrogen in stressed food plants. Oecologia 63:90-105

Xiang FH, Yang W, Chen YF, Yang Z (2010) Acute toxicity of nitrite and ammonia to Daphnia similoides of different developmental stages: using the modified gaussian model to describe. Bull Environ Contam Toxicol 84:708-711

Yang LH (2004) Periodical cicadas as resource pulses in North American forests. Science 306:1565-1567

Yang LH, Bastow JL, Spence KO, Wright AN (2008) What can we learn from resource pulses? Ecology 89:621-634 